\title{
الاستعمال الشرعي للمخدرات في ظل الاتجاهات الحديثة لها
}

$$
\text { جامعة الإخوة منتورية الحقوق بوعون }
$$

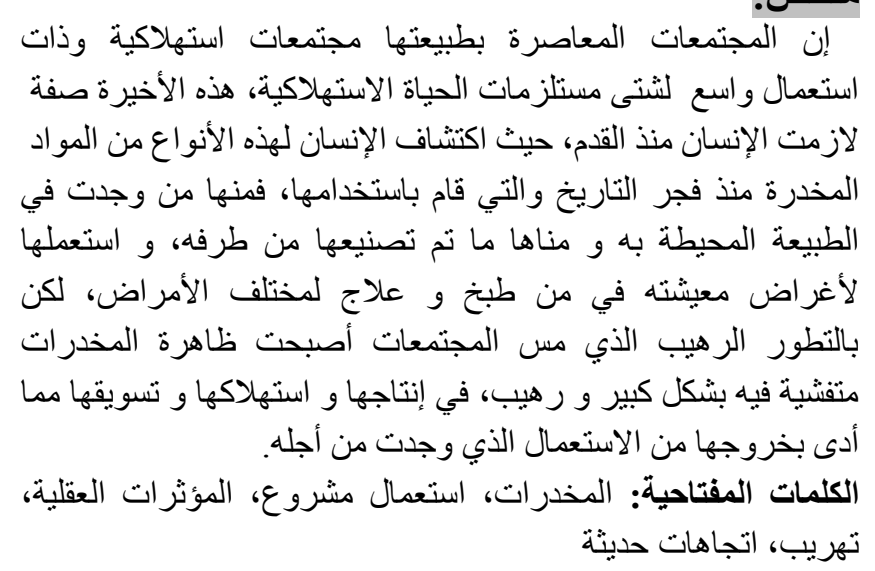

\section{Abstract:}

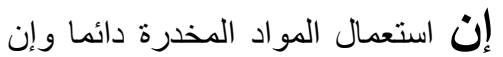

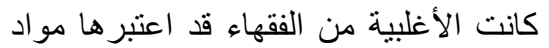

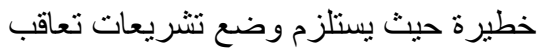

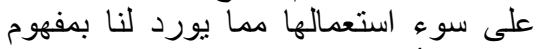
المخالفة أن سوء استعمال المواد المئه المخدرة

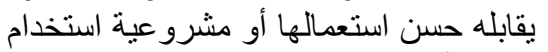
هذه الأخيرة إن نم ذلك بطرق الثرو علمية و

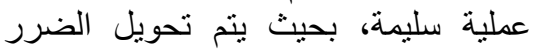

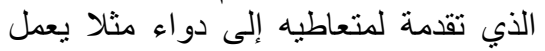

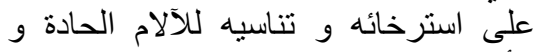
الأمراض التي تصيبه، لكن بعد التطور التطور

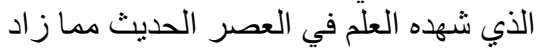

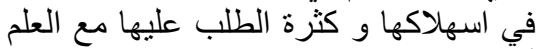

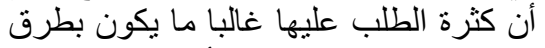

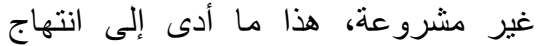

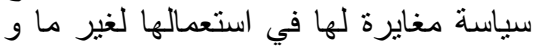

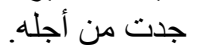

The contemporary societies are inherently consumer and with the use of a wide variety of consumer necessities of life communities, This last recipe haunted man since ancient times, where human discovery of these types of narcotic substances since the dawn of history and by the use, from the mismatch found in the surrounding nature and what was manufactured by him, And used it for the purpose of living in the cooking and treatment of various diseases, but the terrible development that affected societies became a phenomenon of drugs is rampant in a huge and terrible, in production, consumption and marketing, resulting in the exit from the use that was found for it.

Keywords: drugs, legal use, psychotropic substances, smuggling, modern trends 
مما ييرز لنا الاشكالية التالية: هل اقتصر استعمال المخدرات فقط على نحو مشروع و قانوني أم لا ،

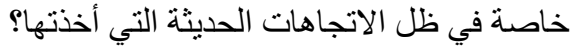
و عليه سوف نتناول اشكالية البحث في ثلاثة محاور كالتالي:

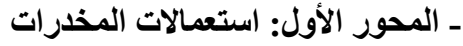

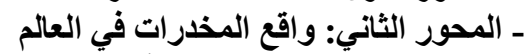

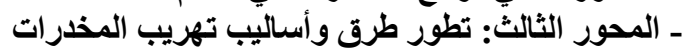

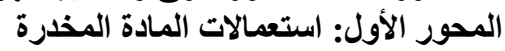

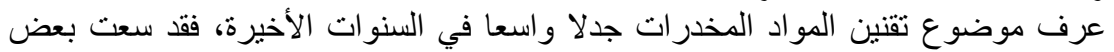

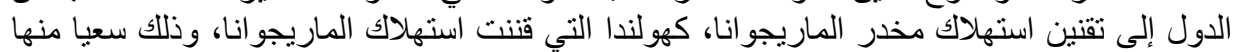

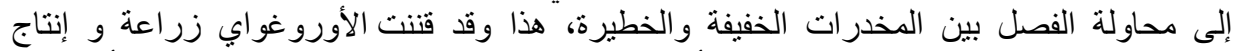

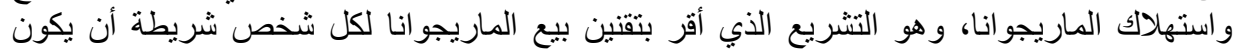

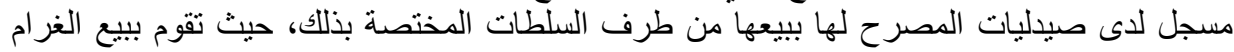

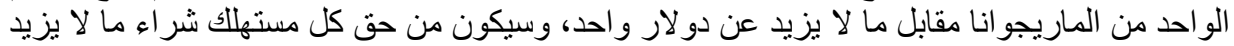

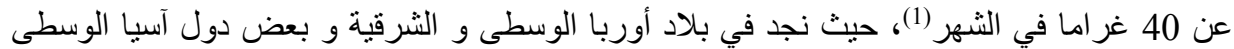

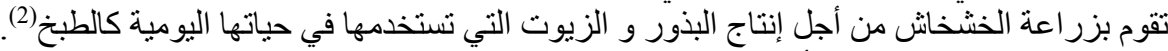

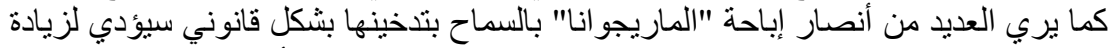

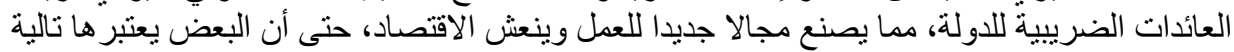

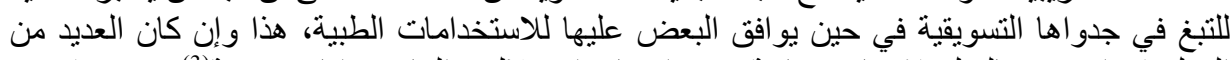

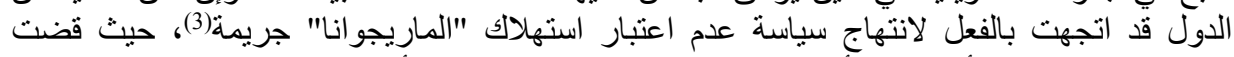

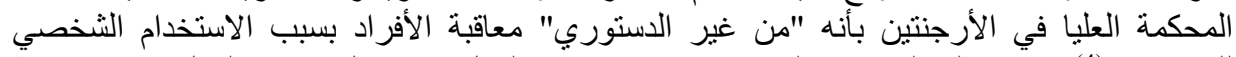

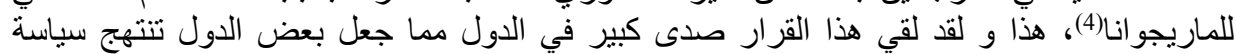

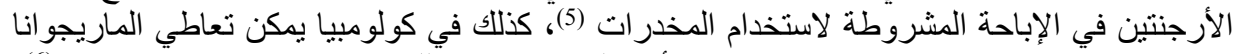

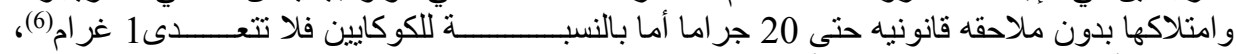

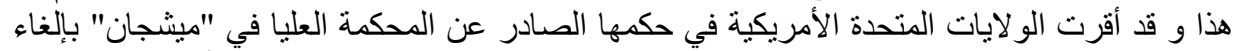

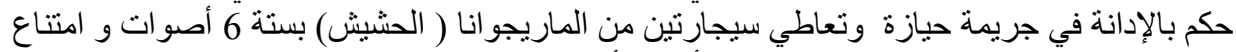

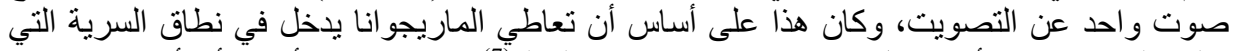

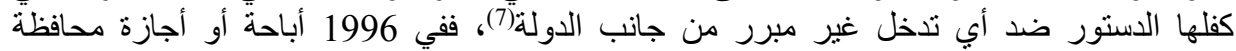

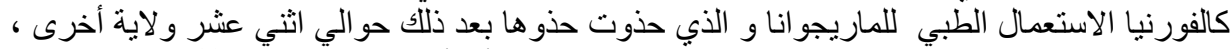

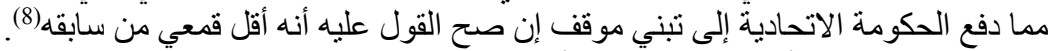

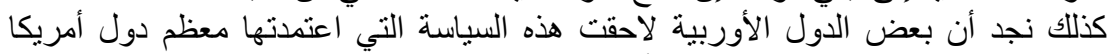

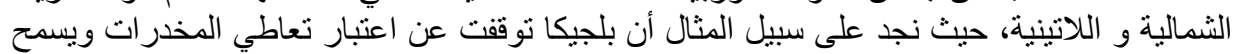

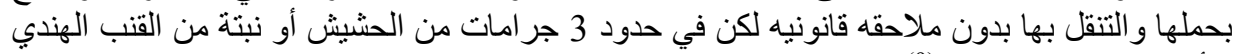

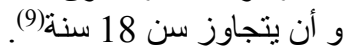

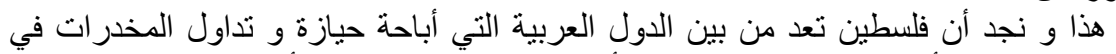

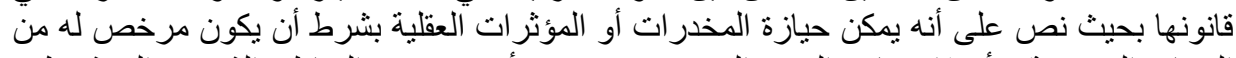

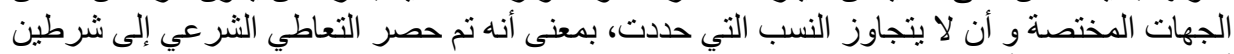

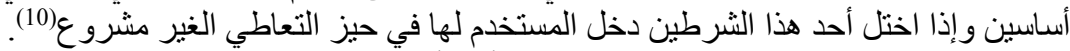

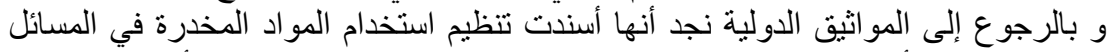

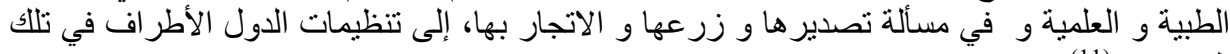
المعاهدات(11) حيث برى بعض علماء الطب النفسي أن تعاطي الحشيش مثلا لا يؤدي إلى الإدمان باعتباره أخطر الحلقات و أكثر ها ضرر الثلما هو الحال في تعطي الخمور و المسكرات و الأفيون و التبغ، كذللك الخدان 


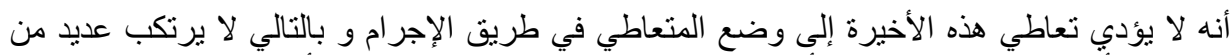

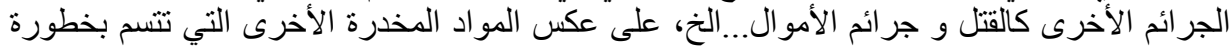

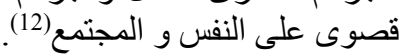

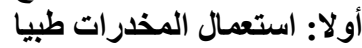

كما ذكرنا سابقا أن الإنسان عرف بعضآ العض النباتات و الأعشاب التي كان يستعملها في علاج

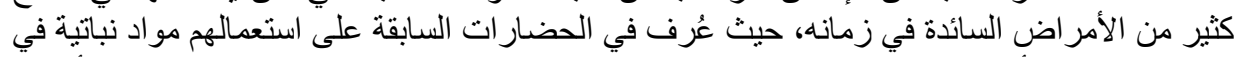

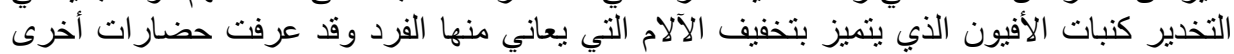

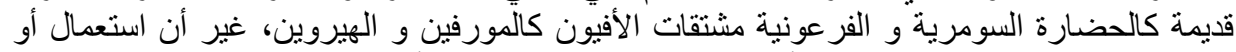

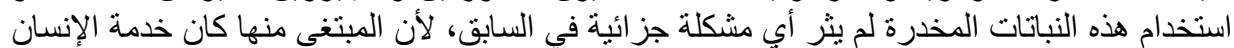

كان أول مؤتمر دولي خاص بالمخدرات في الصين سنة 1909م و الذي دعت إليه الو الو لايات

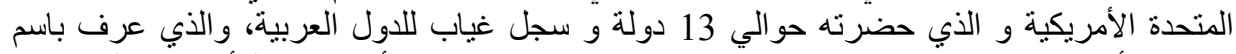

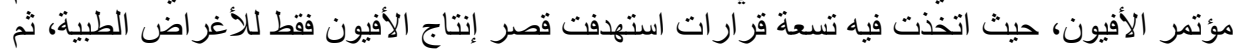

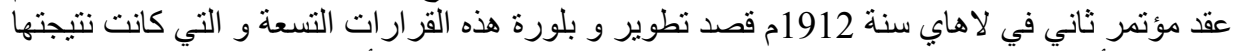

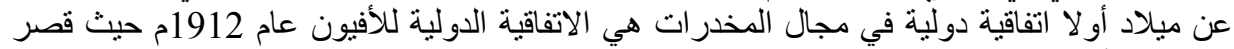

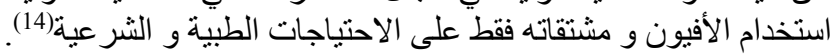

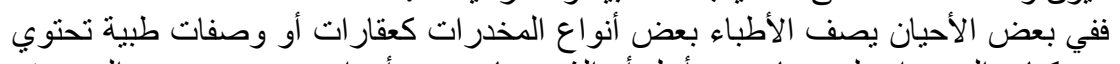

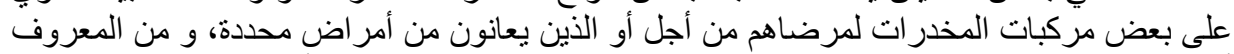

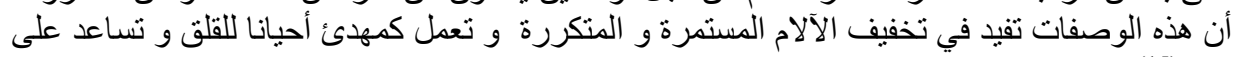

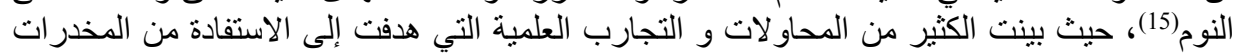

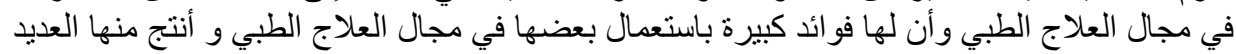

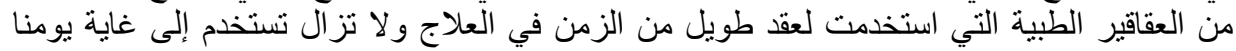

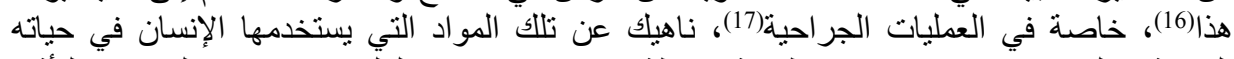

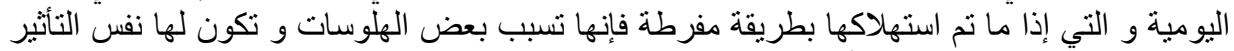

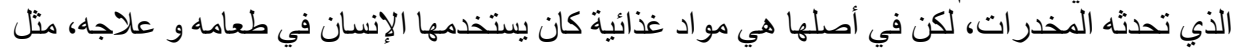

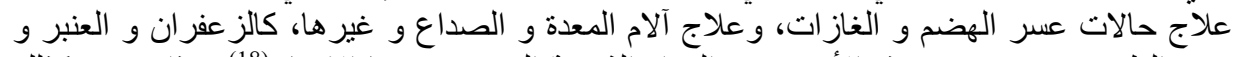

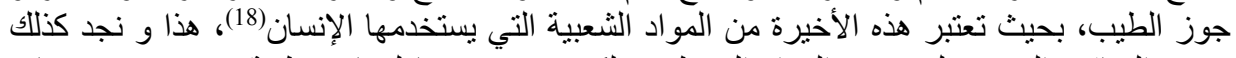

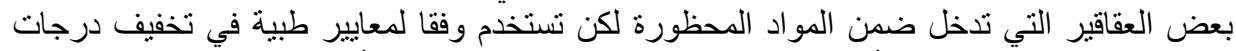

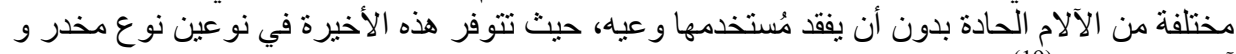
آخر غير مخدر (19).

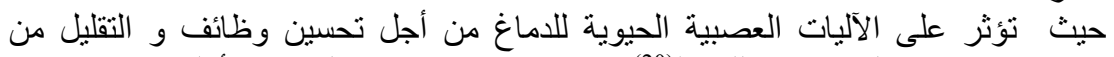

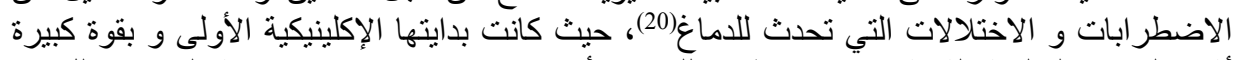

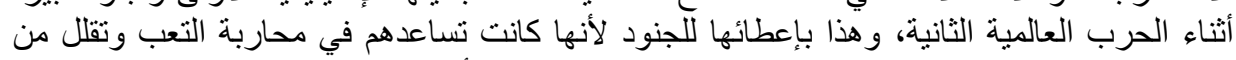

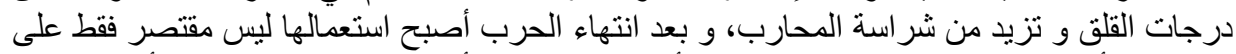

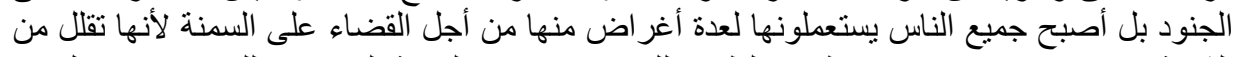

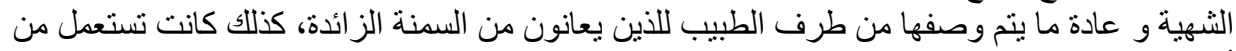

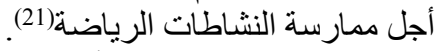

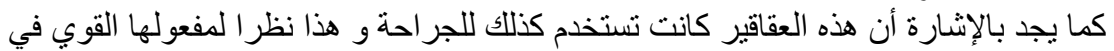

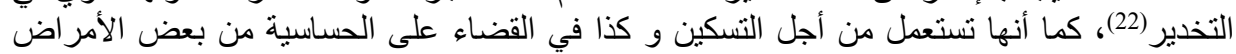

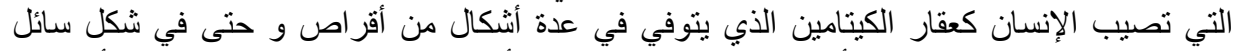

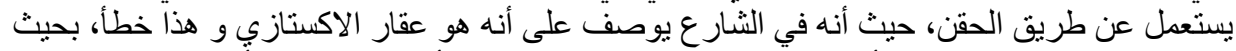
يعمد التجار إلى قول ذلك من أجل زيادة نسبة البيع، لكن يمكن لها أن تعمل بنفس تأثنير مادة الاكستازي 
إذا نم خلطها بمو اد أخرى بحيث يكون لها نفس نأثير هذه الأخيرة(23)، كذلك نجد بعض العقات العاقير التي لها

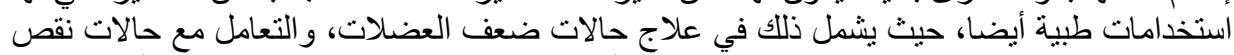

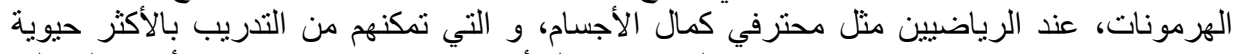

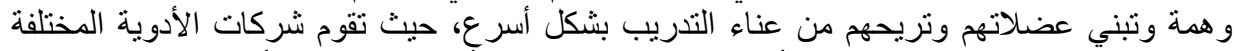

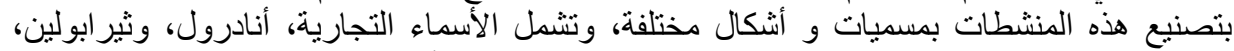

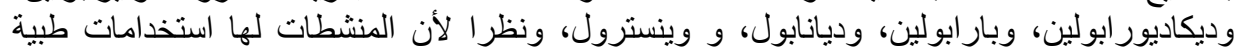

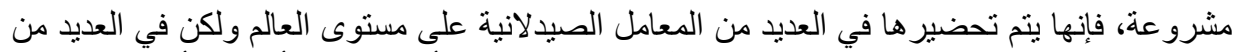

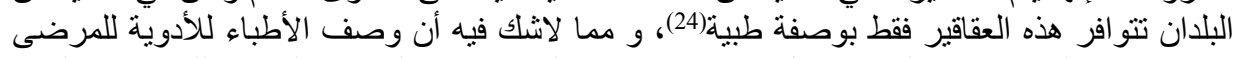

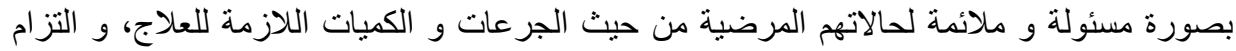

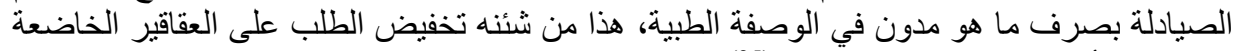

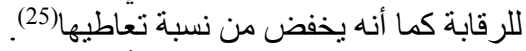

ثانيا: استعمال المو اد المخدرة للأغراض التهاط التجارية

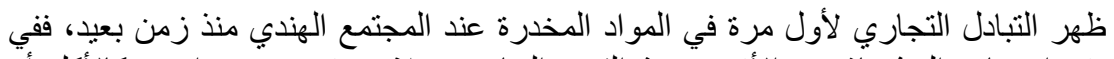

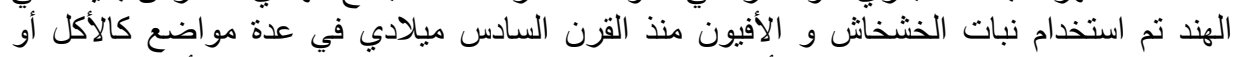

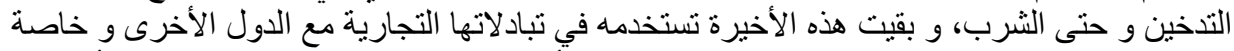

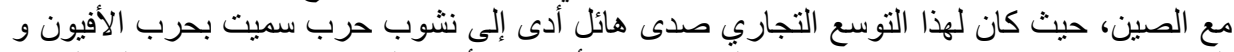

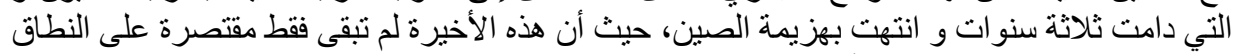

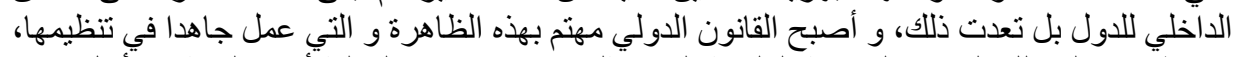

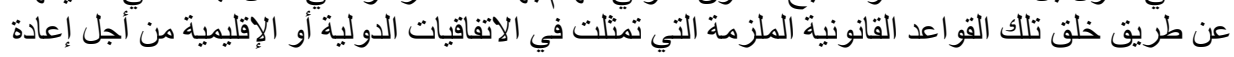

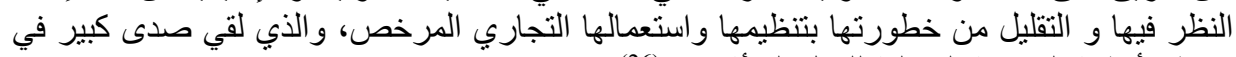

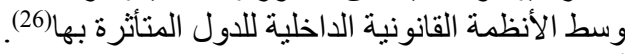

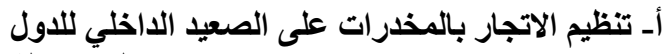

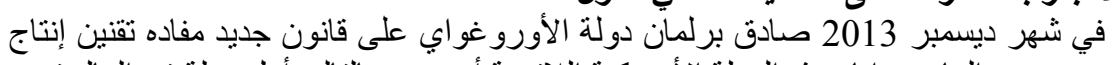

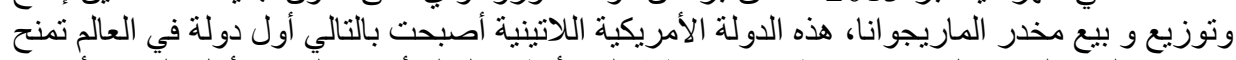

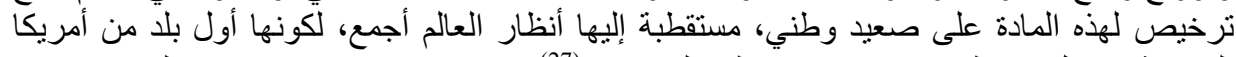

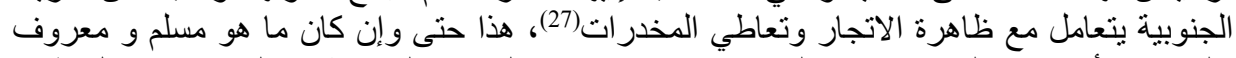

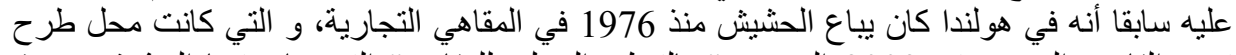

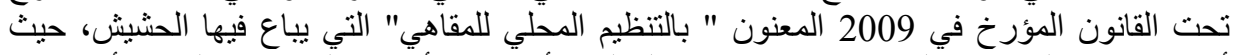

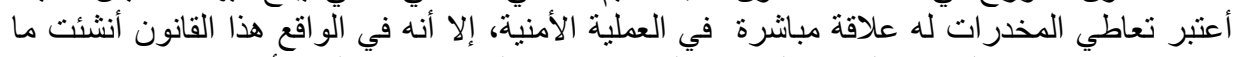

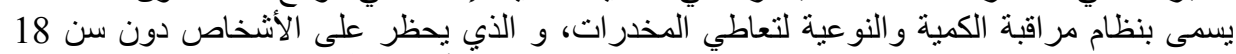

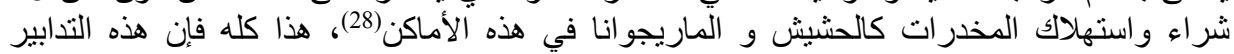

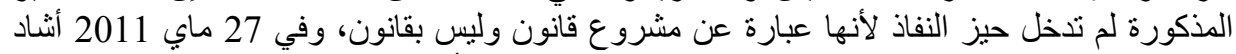

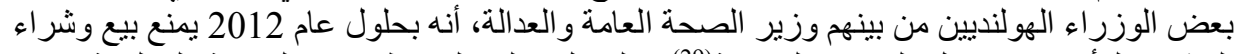

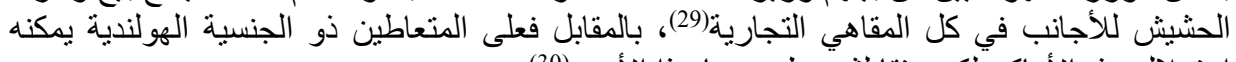

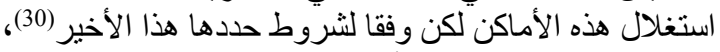

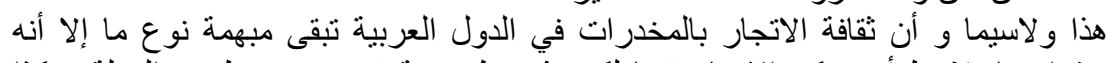

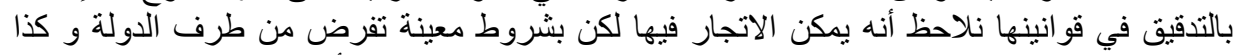

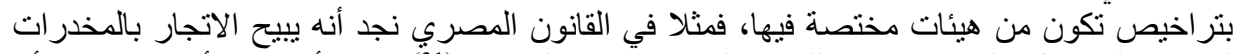

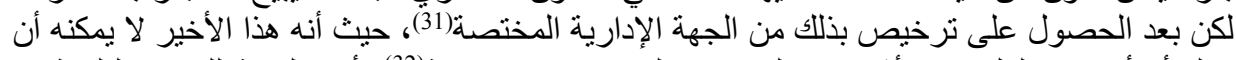

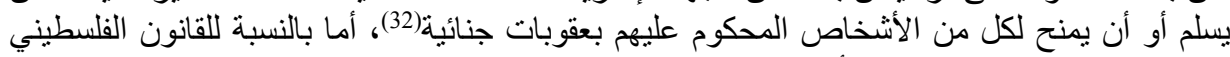

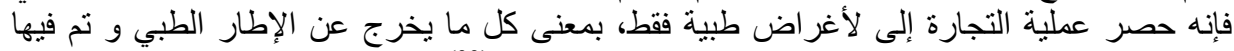
التجارة فهنا يدخل في الاتجار الغير المشروع بالمو اد المخدرة: (33)، هذا و قد حصر المشر الشرع الإمار اتي 


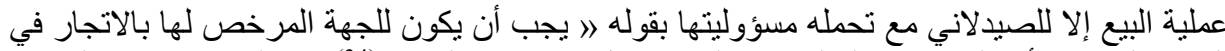

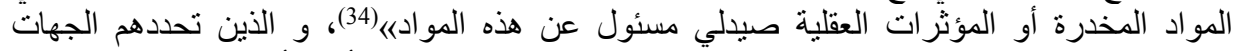

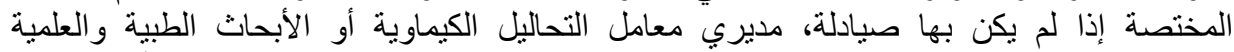

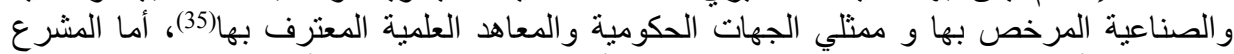

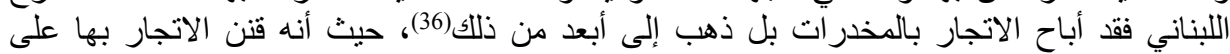

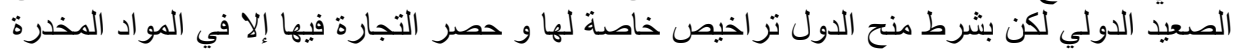

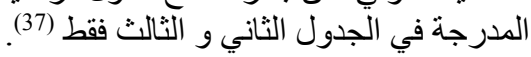
بـ التنظيم الدولي للاتجار بالمخدرات النزات

يرتكز النظام القانوني الدولي في فرض الرئي الرقابة على إنتاج و تجارة و تناول المخدرات

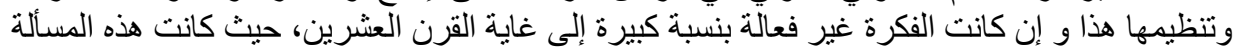

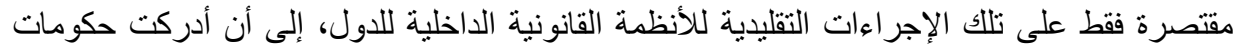

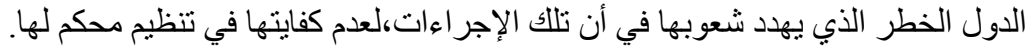

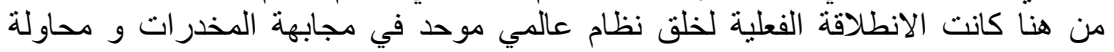
تنظيمها و هذا في عقد الاتفاقية الوحيدة للمخدرات سنة 1961 و و التي دخلت دئ حيز النفاذ النفاذ في 13 ديسمبر

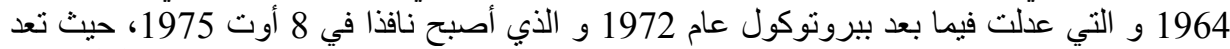

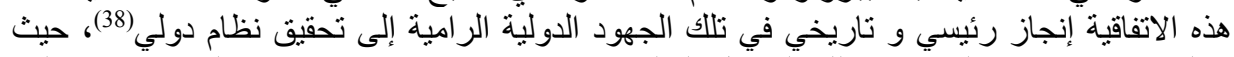

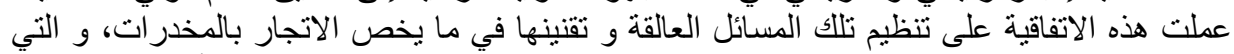

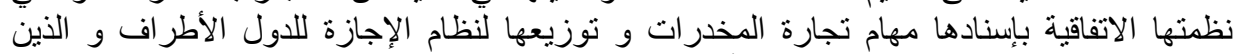

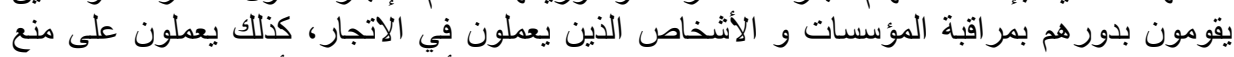

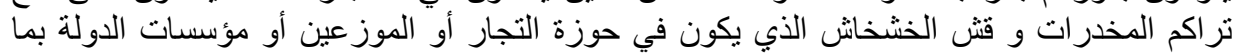

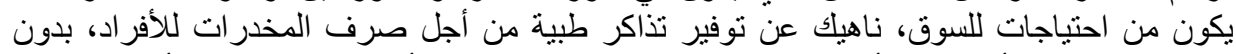

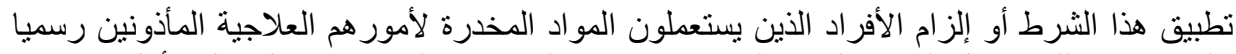

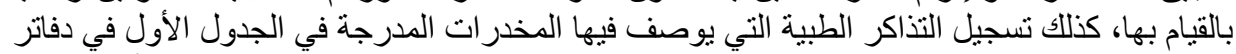

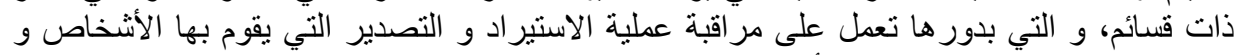

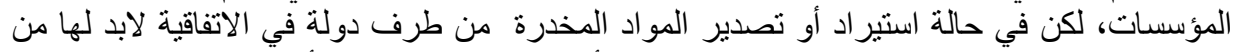

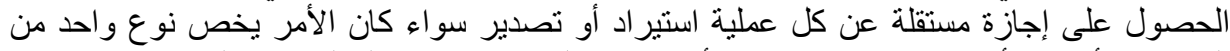

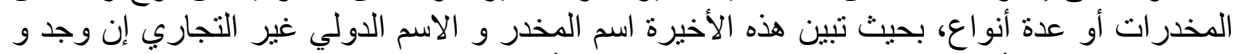

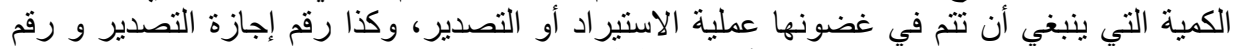

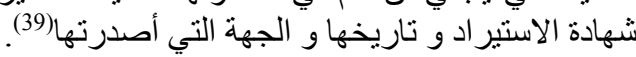

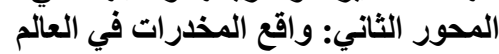

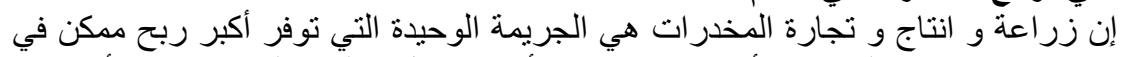

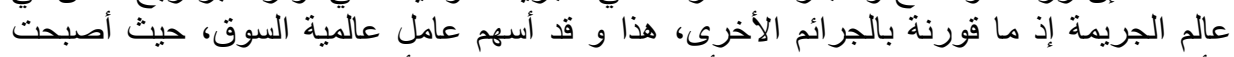

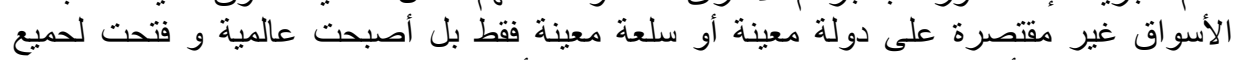

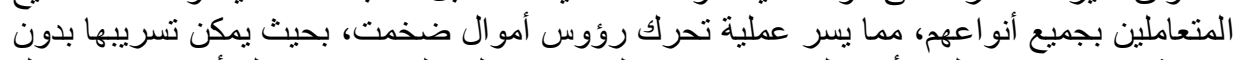

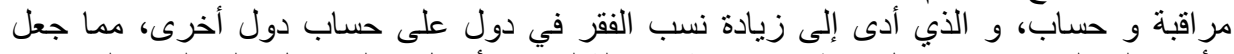

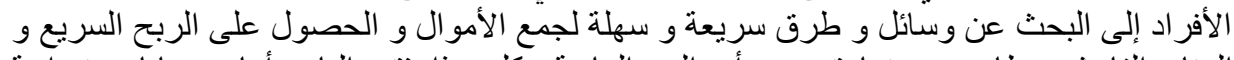

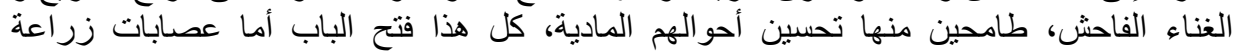

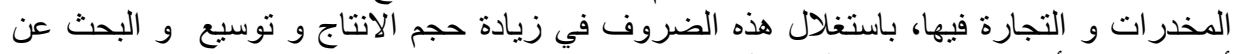
أسواق جديدة أخرى تمكنهم من الربح السريع عن طريق تهرييها و الاتجار فئها خارج مكان التان انتاجها 
أولا: زيادة حجم الإنتاج و تعطي المخدرات في العالم

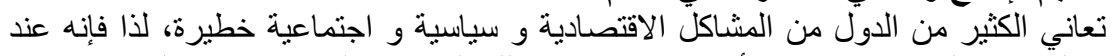

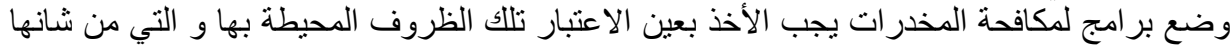

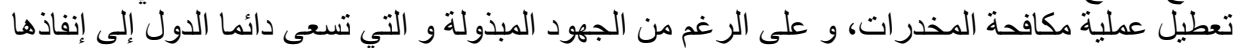

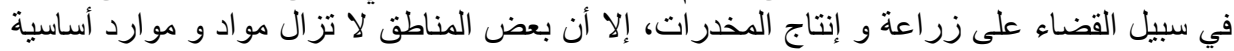

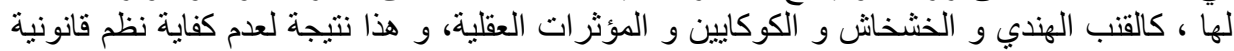

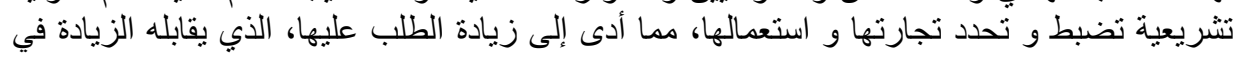

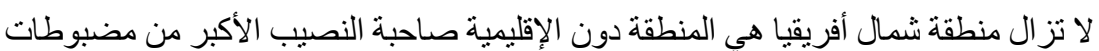

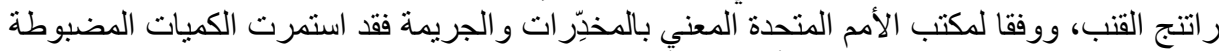

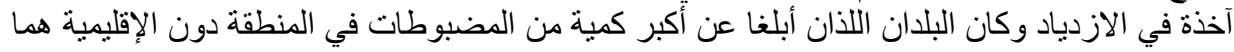

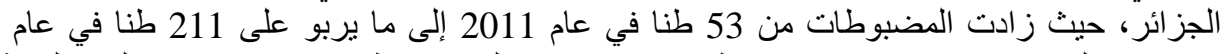

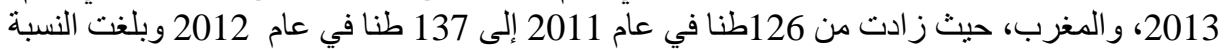

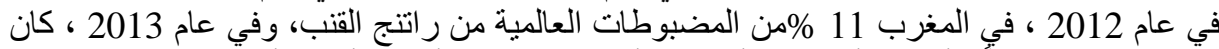

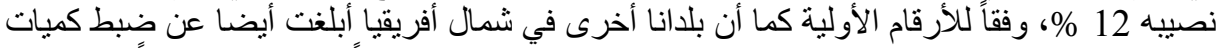

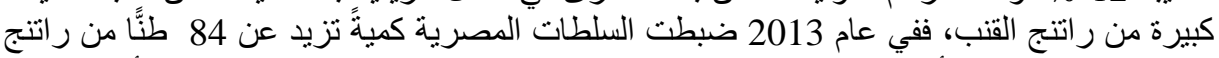

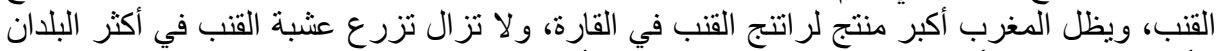

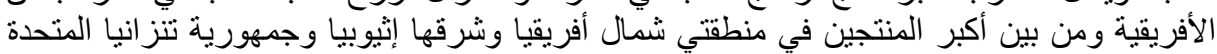

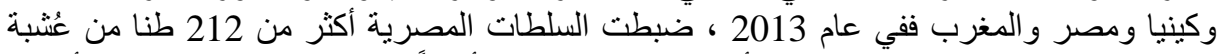

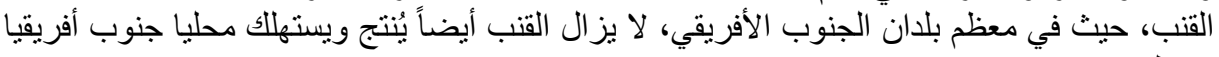

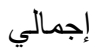

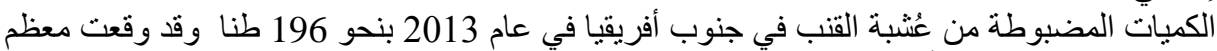

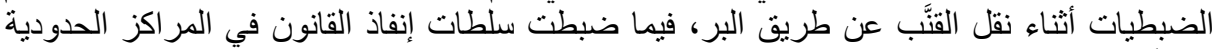

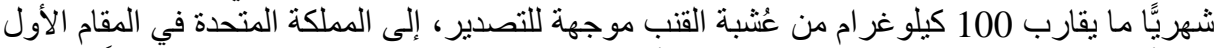

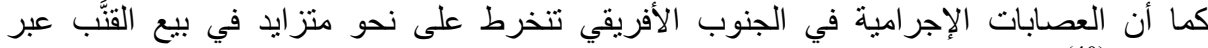

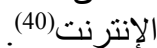

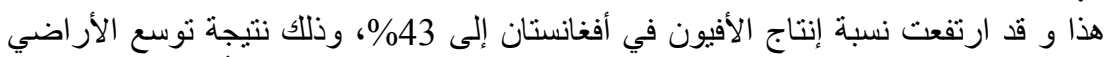

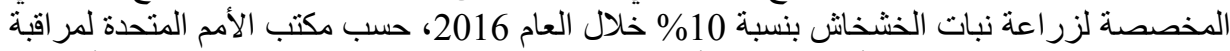

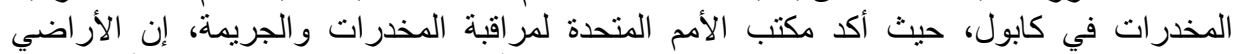

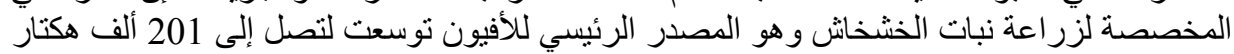

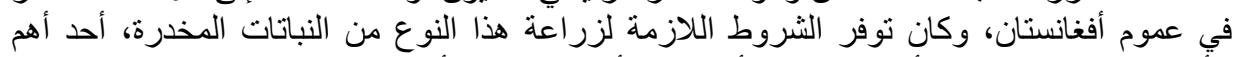

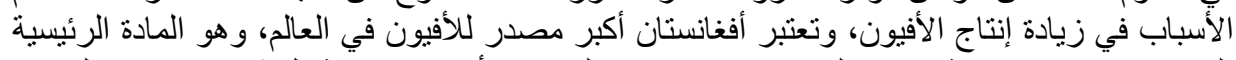

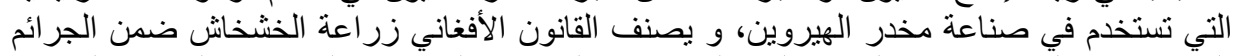

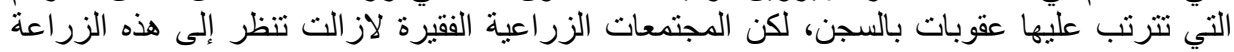
باعتبار ها مصدر دخل رئيسي (41).

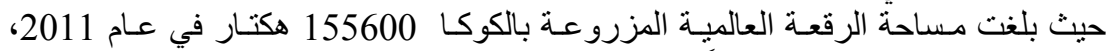

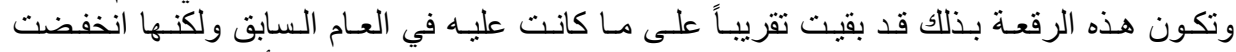

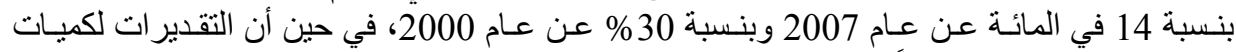

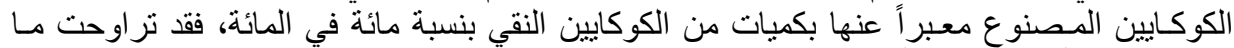

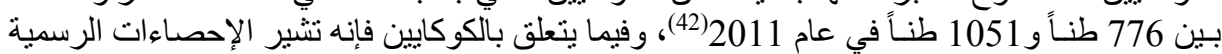

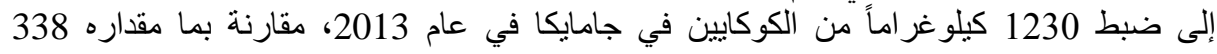




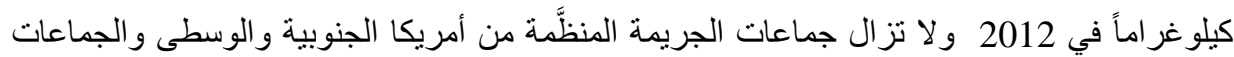
المحلية تستغل ضعف البنى التنظيمية لدى الدولة و الثرطة في البلد ويؤدي الفساد وسهولة التهلي التسلل عبر

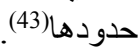

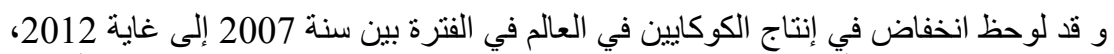

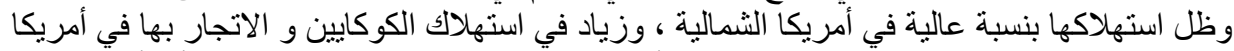

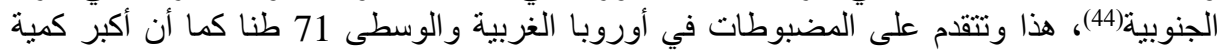

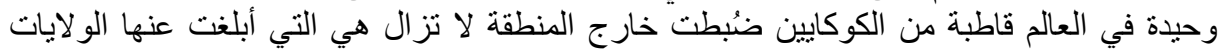

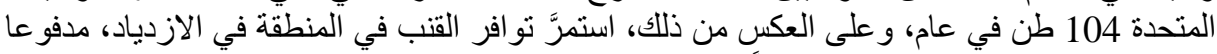

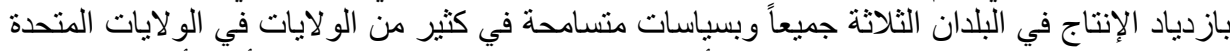

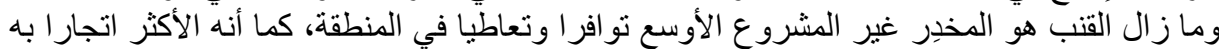

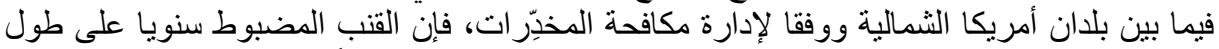

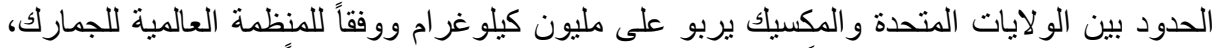

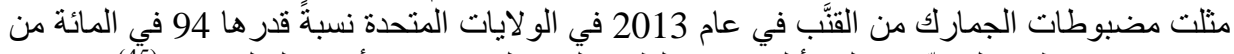

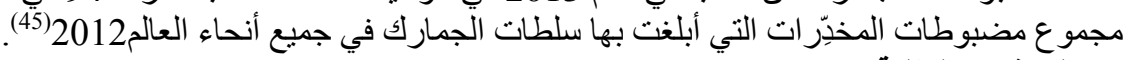
بـ - المؤثرات العقلية

لقد تم تسجيل تز ايد تعاطي المنثِّطات الأمفيتامينية في أفريقيا، مع أنه لا لا توجد بيانات شاملة

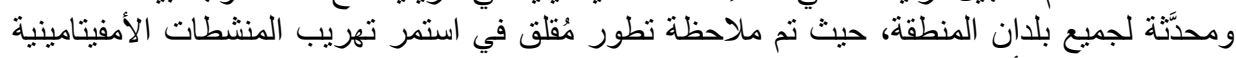

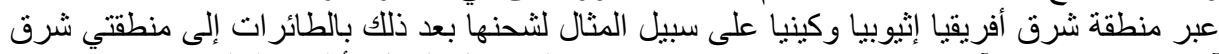

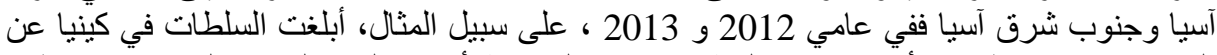

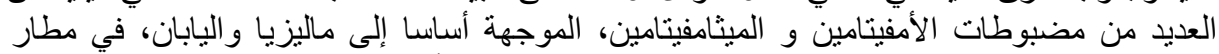

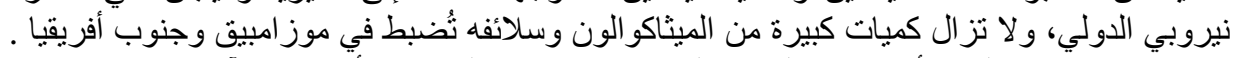

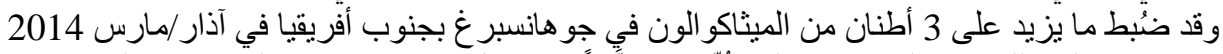

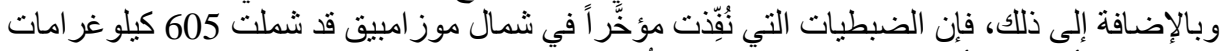

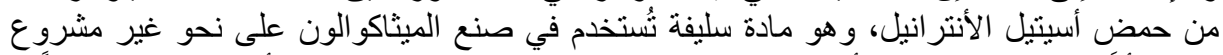

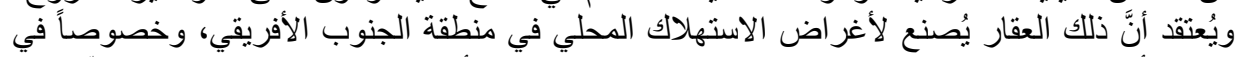

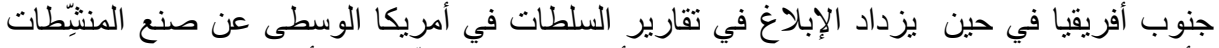

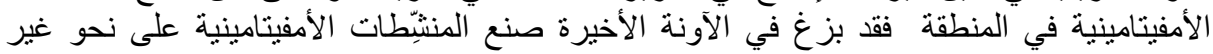

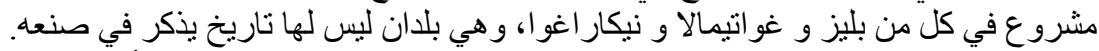

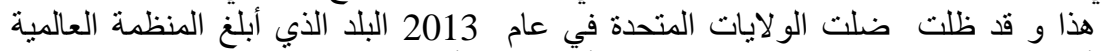

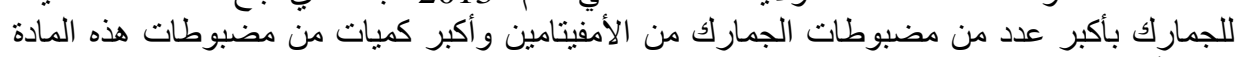

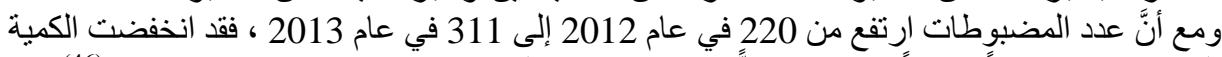

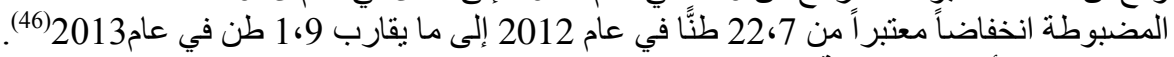

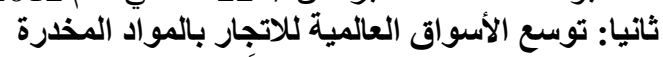

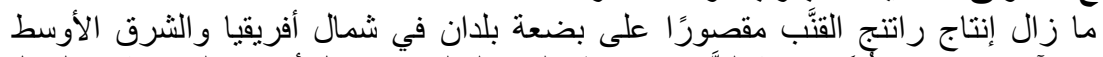

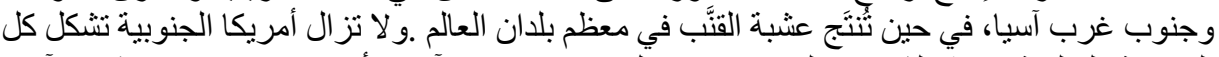

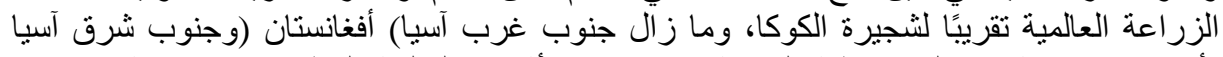

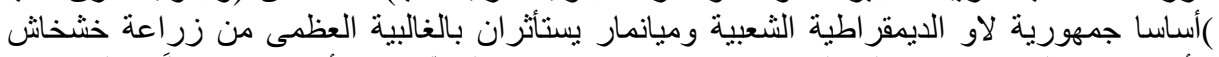

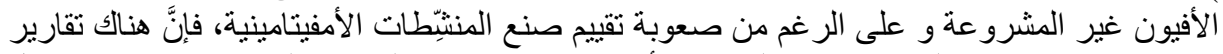

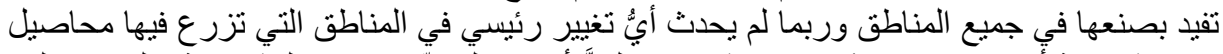

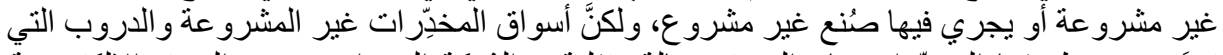

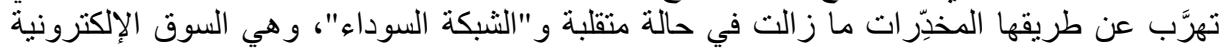

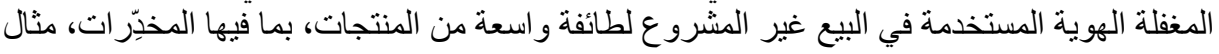


رئيسي للوضع الدائم التغيّر، وتترتب عليها آثار عميقة على أنشطة إنفاذ القانون وعلى الاتجار

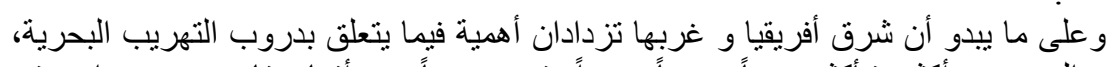

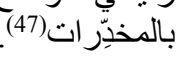

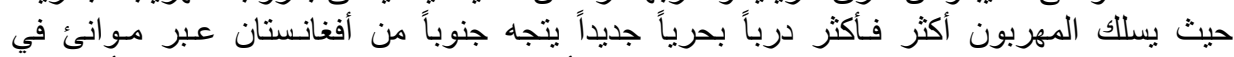

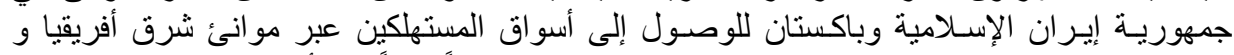

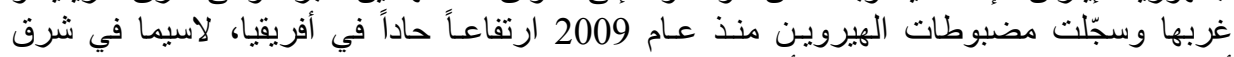

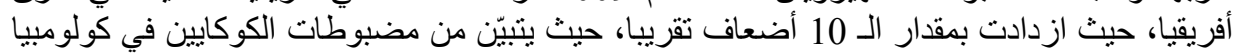

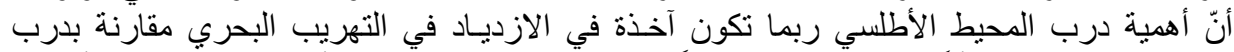

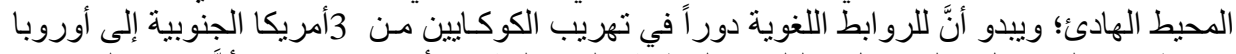

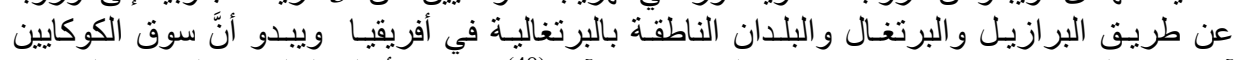

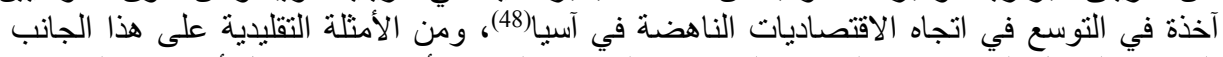

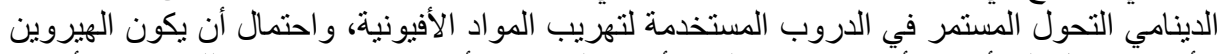

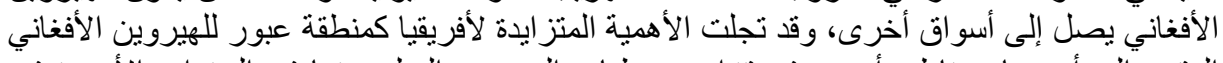

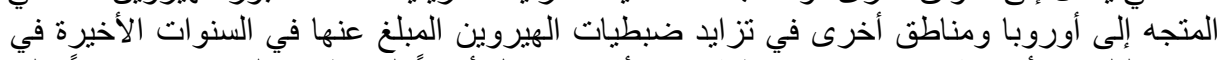

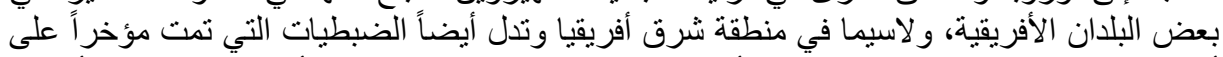

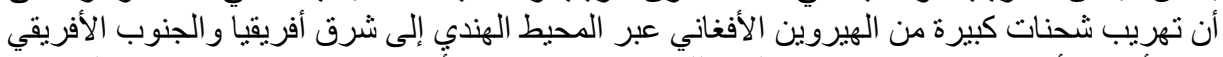

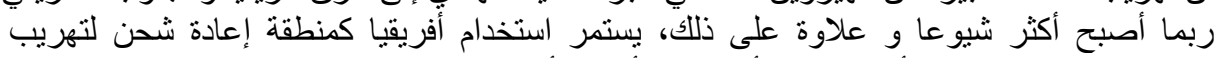

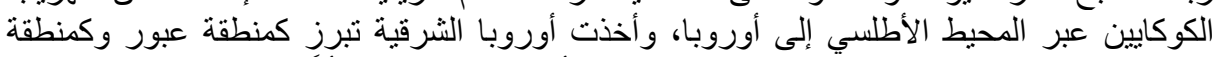

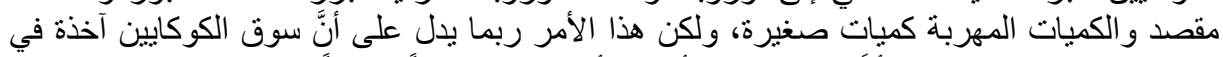

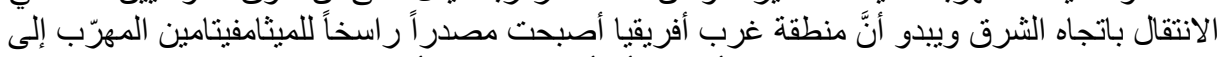

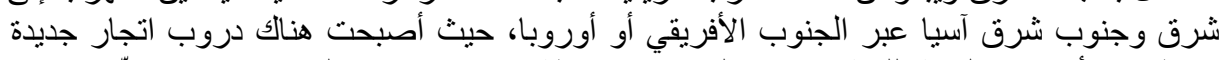

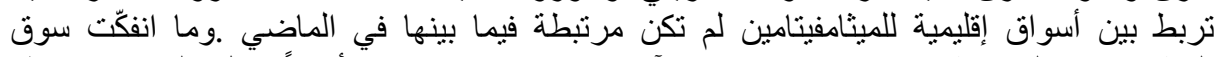

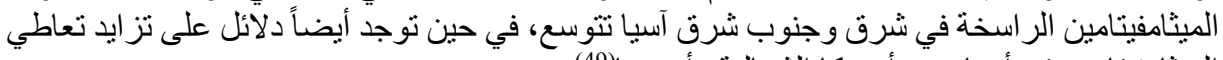

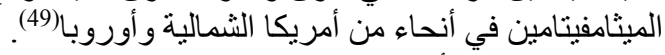

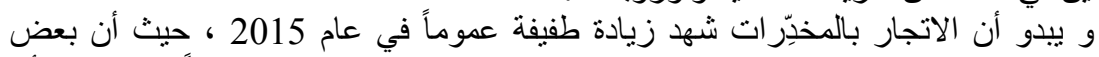

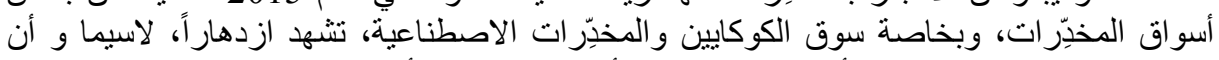

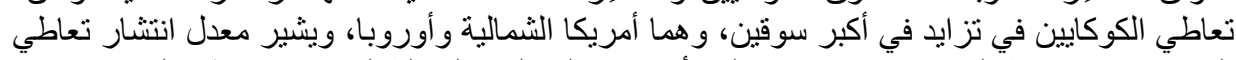

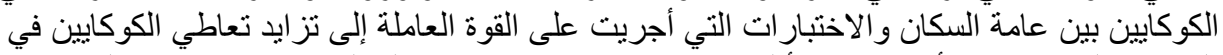

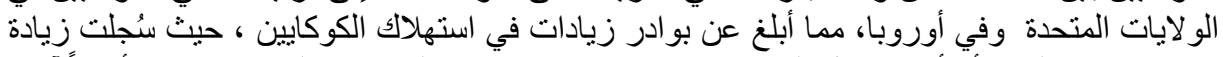

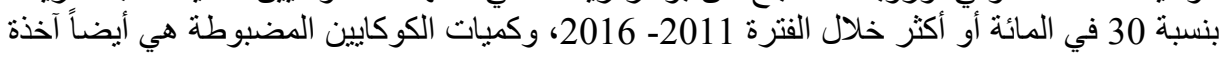

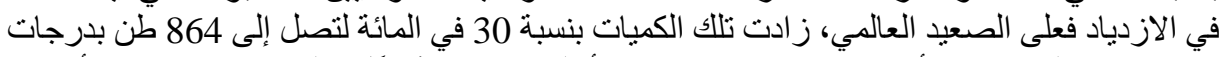

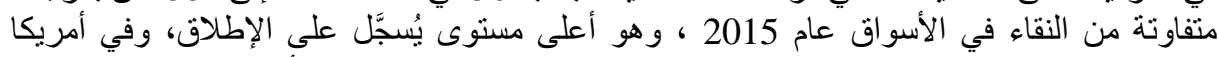

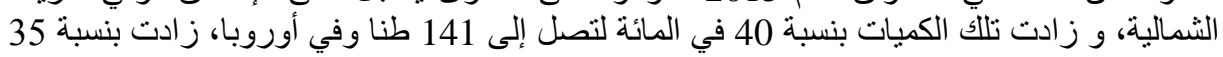

\% لتصل إلى 84 طنا.

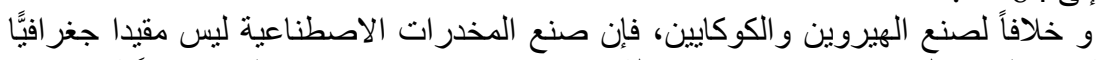

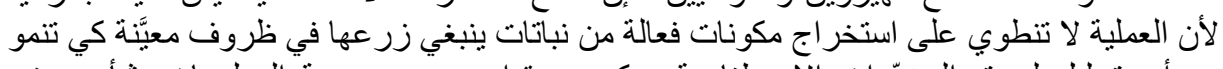

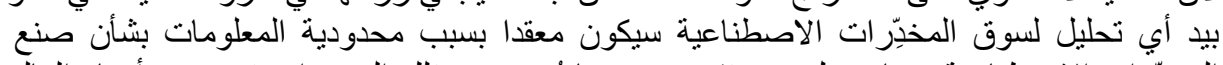

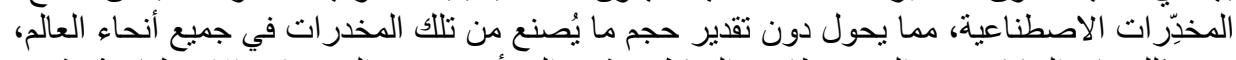

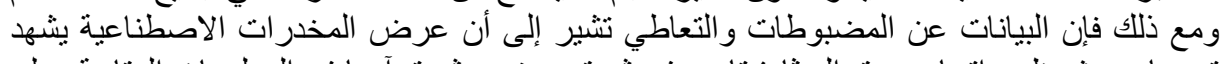

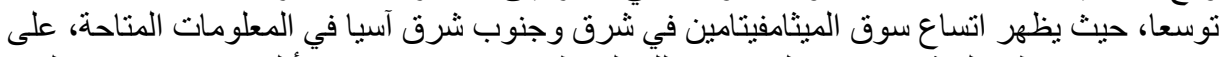

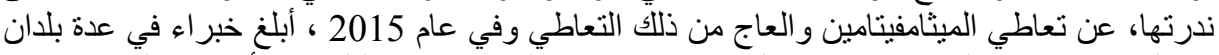

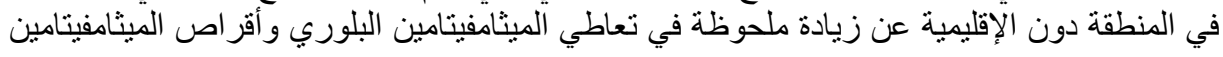




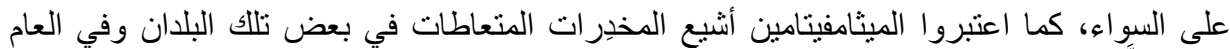

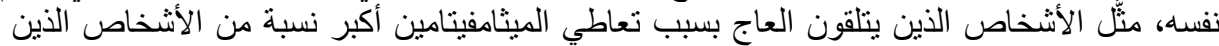

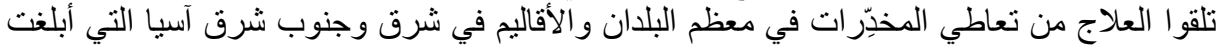
عن ذلك المؤشر (50).

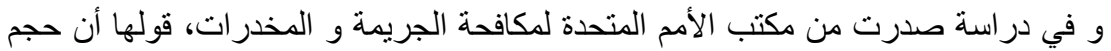

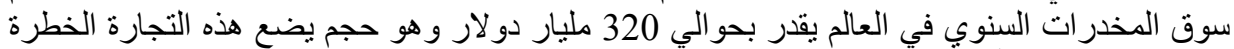

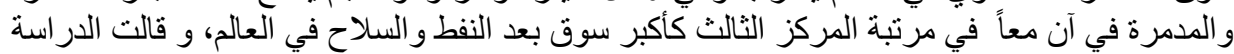

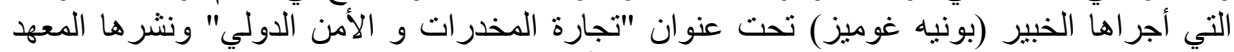

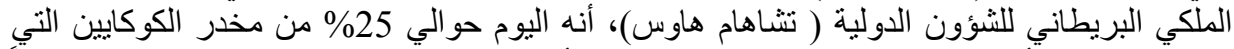

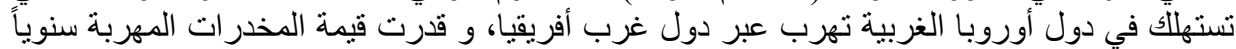

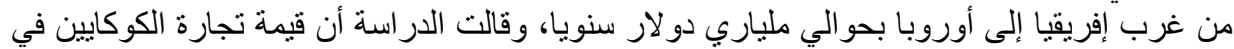

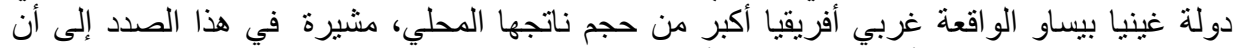

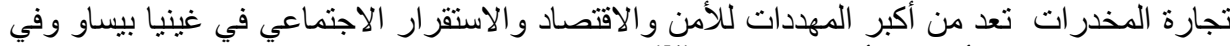

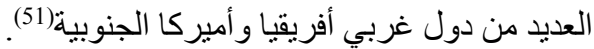

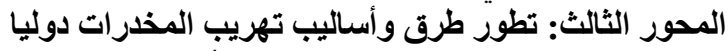

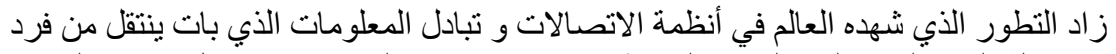

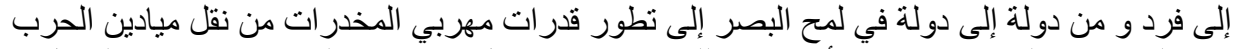

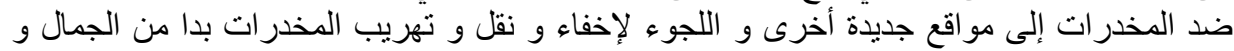

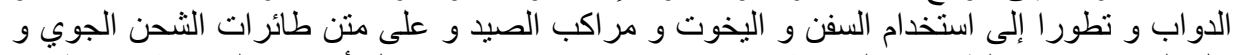

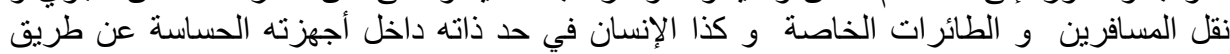
ابتلاعها و إخفائها داخل أمعائه ، إلى جانب إنى إخفائها داخل الرسائل وائل و الطرود المشحونة بالبريد

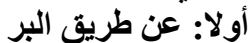

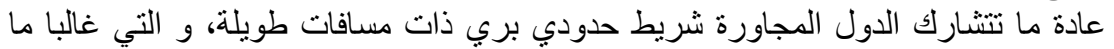

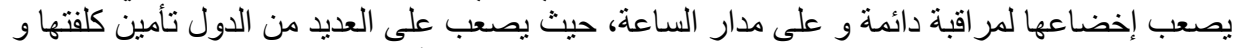

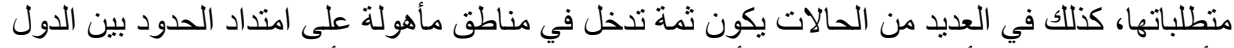

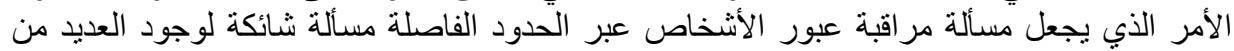

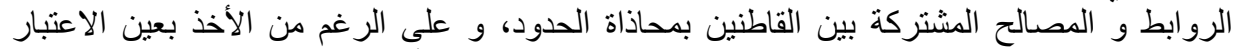

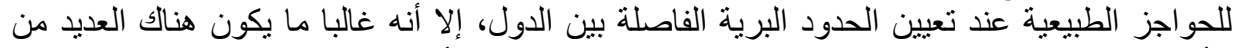

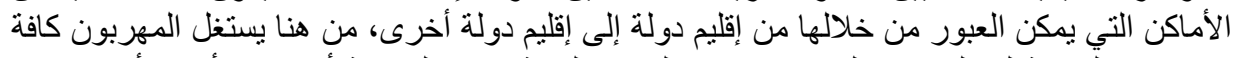

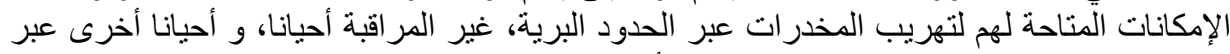

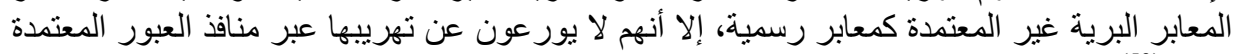

ثُانيا: عن طريق البحر و القتوات المائية

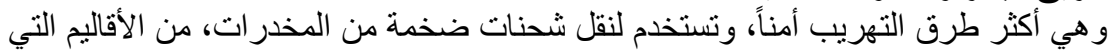

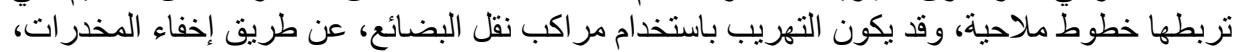

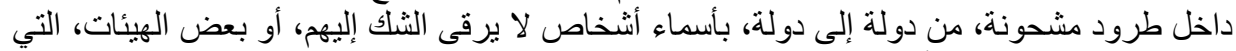

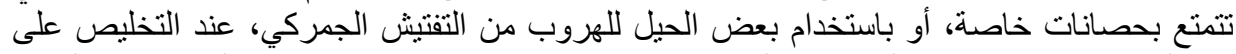

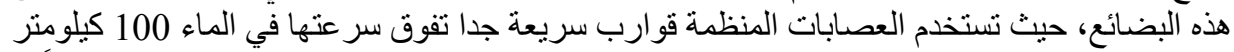

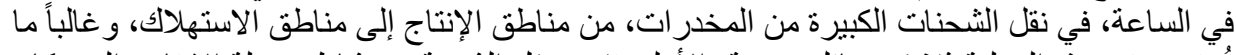
تُشتخدم في هذه العملية ثلاث وسائل بحرية، الأولى تقوم بنقل الثحنة من شاطئ دولة الإنتاجئ الإن، إلى مكان 
توجد فيه السفينة الثانية، التي تتولى النقل في أعالي البحار إلى موقع السفينة ثالثة، بالقرب من المياه الإقليمية لدولة الاستهلاك (54).

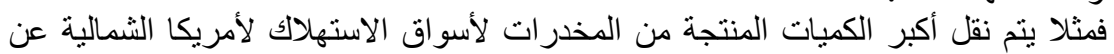

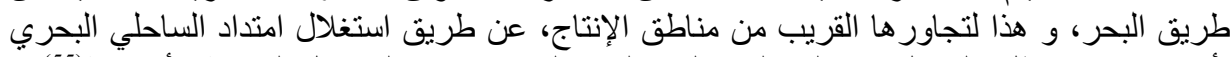

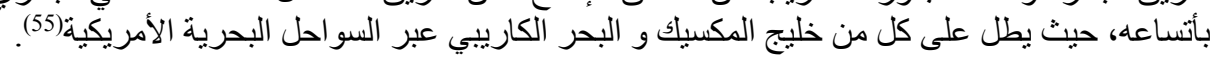

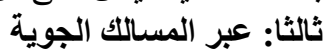

يعتد المهربون في تهريب المخدرات على الطائرات، كوسيلة فعالة لتهريبها، حيث أصبح

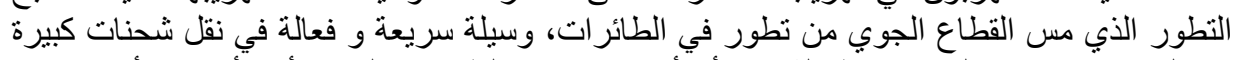

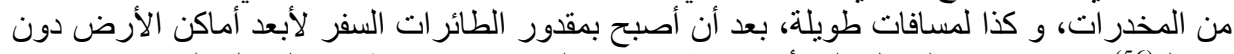

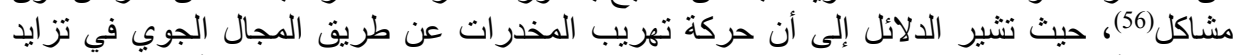

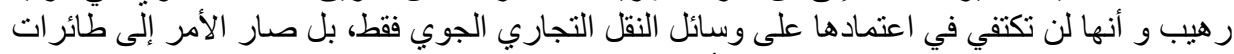

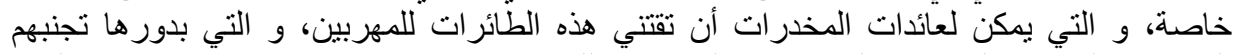

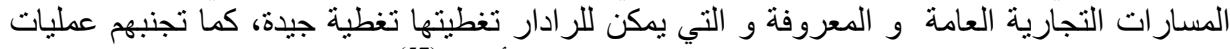

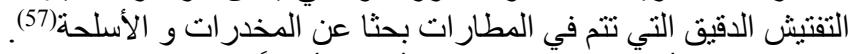

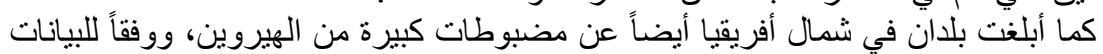

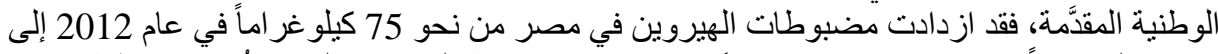

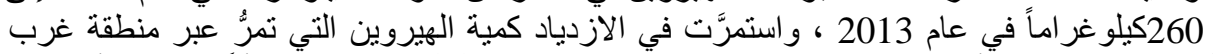

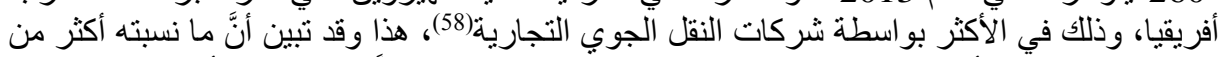

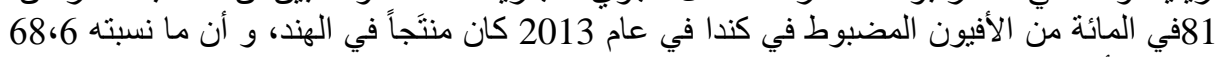

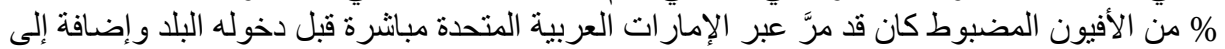

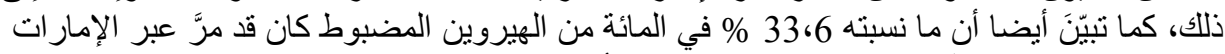

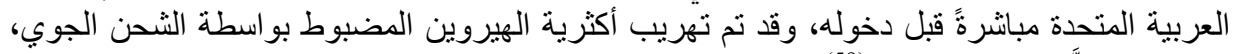

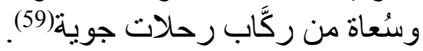

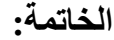

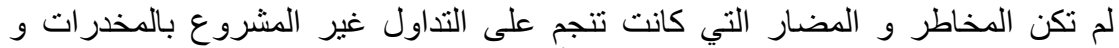

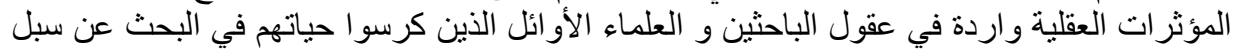

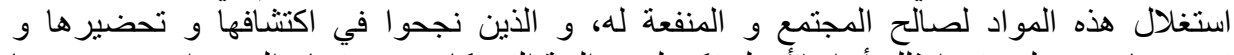

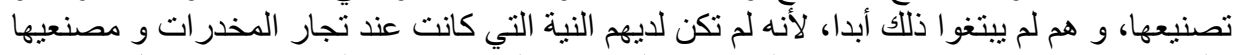

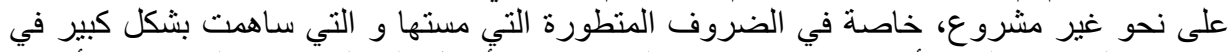

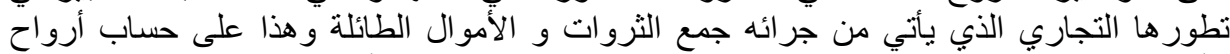

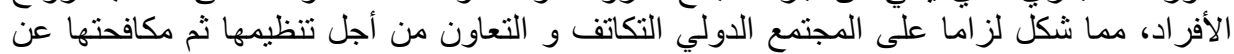

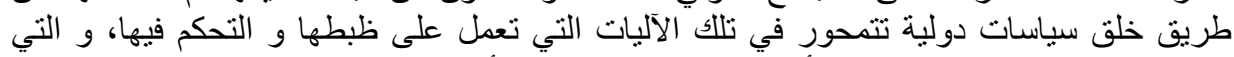

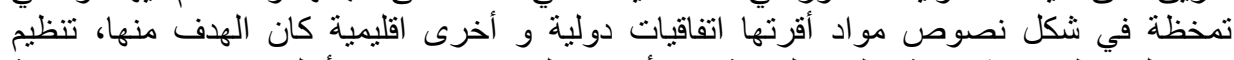

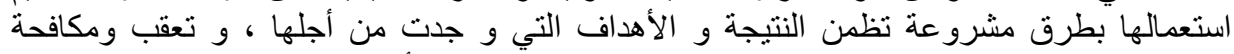

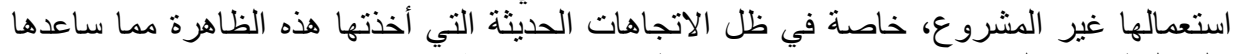
على النطور و الزيادة في انتاجهاو تتسويقها بطرق غير شرعية. 
http://www.bbc.com/arabic/worldnews/2014/05/140503_marijuana_uruguay_t obacco $18.26 \mathrm{~m} . .2017 / 01 / 19$

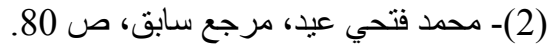

(3)-http://www.akhbarak.net/news/2014/10/04/5093995/articles/16526976 $.2017 / 01 / 1918.40 \mathrm{~m}$

(4) -

http://www.bbc.com/arabic/worldnews/2009/08/090826_me_marijuana_tc2.sht $\underline{\mathrm{ml}} . .2017 / 01 / 19 \quad 18.40 \mathrm{~m}$

$$
\text { ـأنظر كذلك: جريدة Le Monde الفرنسية الالكترونية }
$$
http://www.lemonde.fr/ameriques/article/2009/08/25/l-argentine-avance-vers.. 19:00m.la-depenalisation-du-cannabis_1231937_3222.html 19/01/2017 (5)-http://www.lemonde.fr/ameriques/article/2009/08/25/l-argentine-avancevers-la-depenalisation-du cannabis_1231937_3222.html.. 19/01/2017.. 19:30m (6)- Sentencia C-491/12, La ley colombiana, MEDIDAS PENALES PARA GARANTIZAR LA SEGURIDAD CIUDADANA-Exequibilidad condicionada sobre tráfico, fabricación o porte de estupefacientes. El artículo $2^{\circ}$ de la Ley 30 de 1986, o "Estatuto Nacional de Estupefacientes", definió en su literal, que se considera dosis para uso personal. (7)- محمد مؤنس محب الدين، السياسة الجنائية في مو اجهة المخدرات، دراسة مقارنة، مكتبة الأنجلو

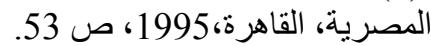
كذلك بالنسبة لمحكمة فلوردا في الو لايات المتحدة الأمريكية ، قد رفضت الطعات الطعن المقدم بعدم دستورية

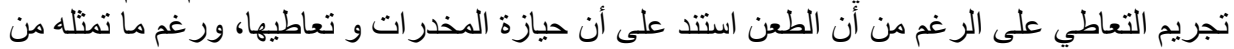

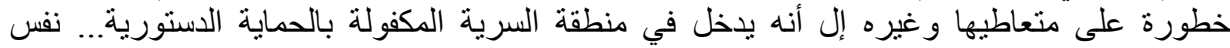

(8)- http://www.courrierinternational.com/article/2009/10/08/le-cannabis-

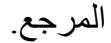
devient-presque-legal...19/01/2017..20.00m.

(9)- Moniteur Belge -Belgisch Staatsblad, Service Public Fédéral Justice, Directive commune de la Ministre de la Justice et du Collège des procureurs généraux relative à la constatation, l'enregistrement et la poursuite des infractions en matière de détention de cannabis, Directives concernant la constatation et l'enregistrement, Directives concernant la constatation et l'enregistrement,2005, P 2569.

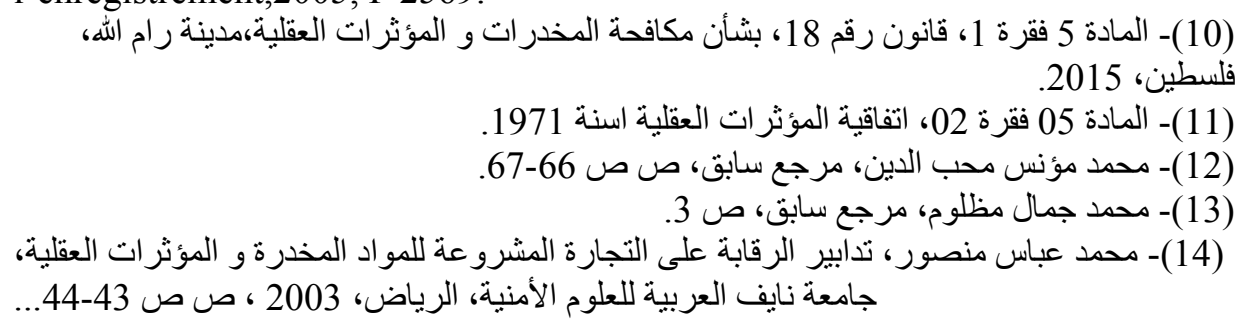


http://www.menafatf.org/images/UploadFiles/Illicit_Trafficking_and_ML_Ar. pdf

(15)- عبد الرحمان محمد أبو عمه، حجم ظاهرة الاستعمال غير مشرو ع للمخدرات، مركز الدراسات الإنات

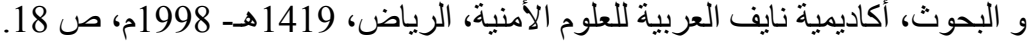

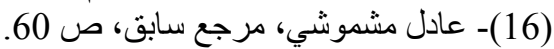

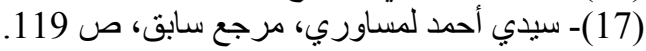

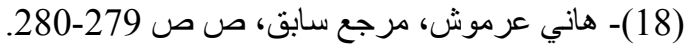

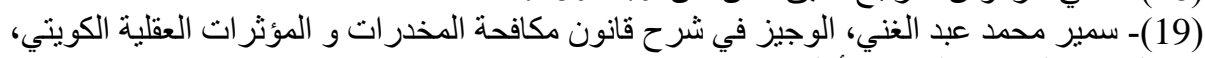

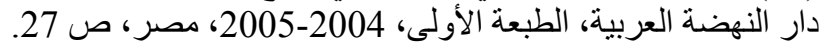

(20)- Réseau PIC, G U I D E D ' I N F O R M AT I O N, Les médicaments

psychotropes, Psychiatrie et Santé mentale, Edition 2014, Paris, P 18.

(21)- GILLES LANDRY, Op, cit, p p 25-26.

(22)- Classeur-Des-Drogues-Luciole, P $6 \ldots$ http://www.laluciole.info/classeur-

des-drogues-luciole.pdf.

(23)- Classeur-Des-Drogues-Luciole, Op, p 24.

(24)- http://www.ginad.org/ar/drugs/drugs/210/anabolic-steroids..22/01/2017

15:45m.

(25)- سمير محمد عبد الغني، مكافحة المخدرات في عصر العولمة، المخدرات و الجريمة و الفساد الإداد

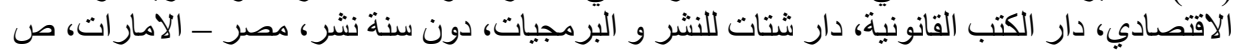

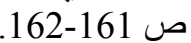

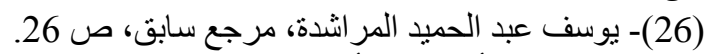

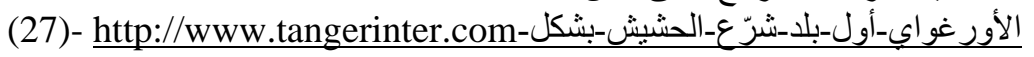

تام//\#.WM_mUtIpzs0 ... 24/01/2017.. 14:45m.

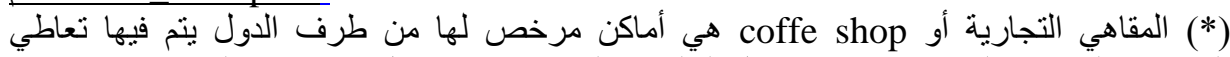
المخدر ات لكن وفق لشروط محددة من قبل السلطات المعنية، نوجد بشكل كبير في هولندا.

(28)-_ Clamé-Ocnam Daméus, PROCESSUS MULTILATÉRAL DE SÉCURISATION DE L'USAGE DE DROGUES, MÉMOIRE PRÉSENTÉ COMME EXIGENCE PARTIELLE DE LA MAÎTRISE EN SCIENCE POLITIQUE, UNIVERSITÉ DU QUÉBEC À MONTRÉAL, JANVIER 2012, P 131... http://www.archipel.uqam.ca/4435/1/M12363.pdf

(29)- Ibid, p 131.

(30)- Arret dans l'affair C-137-09, Marc Michel Jose Mans VS Burg Emeester Van Maastricht, Cour De Justice De L'Union Européenne, Communique De Presse $\quad \mathrm{N}^{\circ} \quad 121 / 10, \quad$ Luxembourg, 16/12/2010. http://curia.europa.eu/jcms/upload/docs/application/pdf/2010-

12/cp100121fr.pdf

(31)-http://www.lemonde.fr/europe/article/2012/04/26/pays-bas-la-bataille-descoffee-shops_1691751_3214.html..

24/01/2017.. 17:15m.

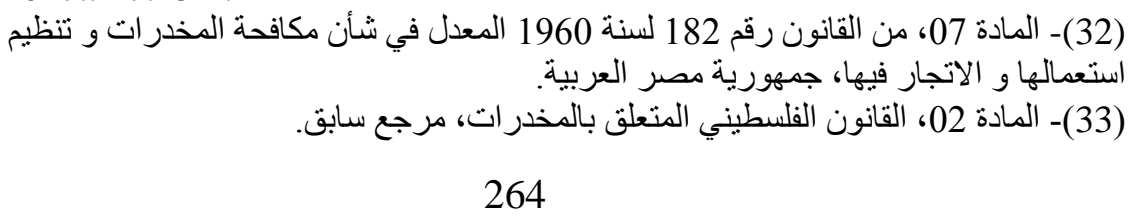


(34)ـ المادة 18، القانون الاتحادي الإمار اتي لمكافحة المو اد المخدرة و المؤثرات العقلية رقم 14/

(35)- المادة 20، نفس المرجع.

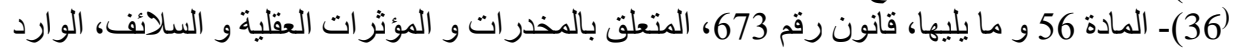

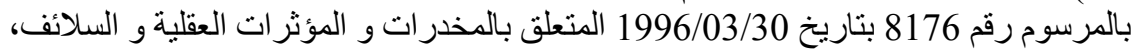

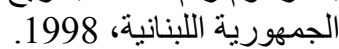

(37)- المادة 08 ف 04، الاتفاقية الوحيدة للمخدر ات لسنة 1961 بصيغتها المعدلة ببروتوكول سنة

(38) - (39) - نفس المرجع (30)

(39)- المادة 30 و 31 من الاتفاقية الوحيدة للمخدر ات 1961 1961، المادة 16 من اتفاقية الأمم المتحدة

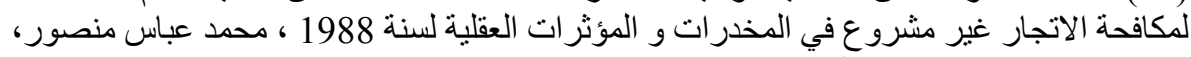
مرجع سابق ، ص 59 و و ما يليهاً...

(40)- تقرير 2014، الهيئة الدولية لمر اقة المخدر ات، مرجع سابق، ص ص صل 45-46-47 16 (41)

(42)- تقرير المخدر ات العالمي لسنة 2013 خلاصة و افية، مكتب الأمم المتحدة المعني بالمخدرات و

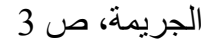

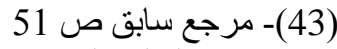

(45)- عبد العالي الدريبي، الاتجار غير مشروع بالمخدرات و الجهود الدولية للوقاية منها بالتطبيق الإنيق

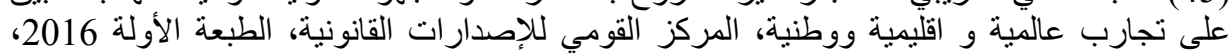

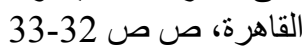

(46)- تقرير الهيئة الدولية لمراقبة المخدرات 2014، نفس المرجع، ص ص صـ 58-59

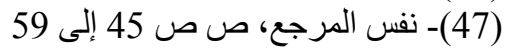

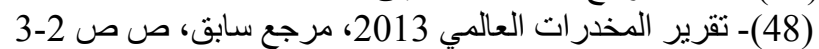

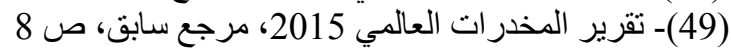

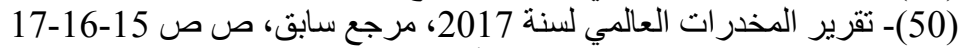

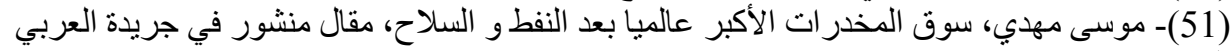

الجديد،

سوق- المخدراتـ الأكبر - عالمبا- بعد- سhttps://www.alaraby.co.uk/economy/2014/2/7 30/04/2018.17:00m النفط- و السلاح

(52)- علي أحمد راغب، الاتجار غير مشروع في المخدرات و المؤثرات العقلية، جامعة نايف العربية

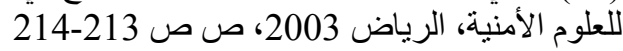

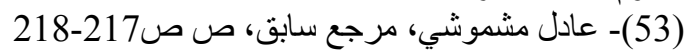

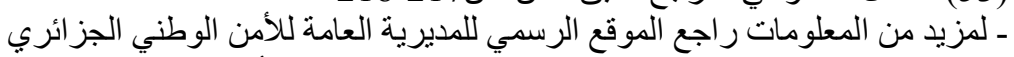

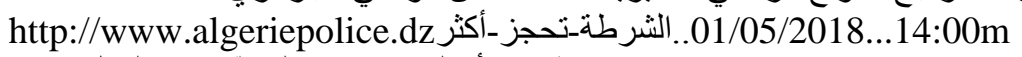

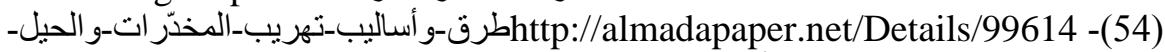

المستخدمة_في_التهريب-_القسم-الأخير 13:30........ 01/05/2018

- voir aussi: https://www.lejdd.fr/Societe/Faits-divers/Le-Pacifique-nouvelleroute-de-la-cocaine-845117... 01/05/2018...13:45m

ـ أنظر كذللك عادل مشموشي، مرجع سابق ص 218 مارون

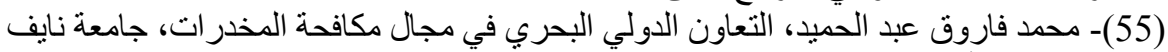

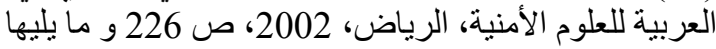

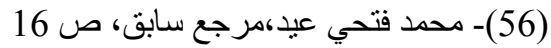


(57)- تقرير الهيئة الدولية للمخدرات لعام 2017، مرجع سابق، ص 51 صابق

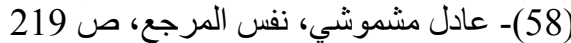

(59)- تقرير الهيئة الدولية لمر اقبة المخدرات لسنة 2014، مرجع سابق ص 46. 